\title{
Balancing drug availability and patient safety
}

\author{
Stephen B Hanauer
}

Over the past 7 years, the US FDA has been under attack from numerous directions over its mission "To promote public health by promptly and efficiently reviewing clinical research and taking appropriate action on the marketing of regulated products in a timely manner." (http://www.fda.gov/oc/oms/ofm/budget/2001/ fdamission.htm). What is rarely understood by physicians, both within and outside the US, is that the FDA is an authority that regulates the marketing of drugs by pharmaceutical companies, not the prescription of drugs by physicians. Physicians' drug prescribing is controlled by state licensing boards, and the appropriateness (or not) of those prescriptions is determined in US courts according to locally determined standards of care.

Unfortunately, third-party payers have begun to determine whether prescriptions are appropriate for their enrollees on the basis of FDAapproved drug labeling. Their decisions are not based upon medical evidence or individual needs, but, primarily, upon financial considerations. Many patients discover that they have inadequate insurance coverage or receive inadequate reimbursement for therapies that have been defined as appropriate by well-conducted research and medical organization guidelines. Additionally, physicians are being burdened by extraordinary administrative demands that must be met to justify the use of appropriate therapies to third-party payers. Physicians receive no additional reimbursement for the administrative efforts required in the (often unsuccessful) attempt to provide optimal patient care.

Most recently, the FDA has been condemned by physicians and third-party payers alike over its mission "...to protect the public health by ensuring that ... human and veterinary drugs are safe and effective..." (i.e. not effective, then safe) (http://www.fda.gov/oc/oms/ofm/budget/2001/ fdamission.htm). The FDA has been strongly criticized over the safety of approved drugs such as rofecoxib, but has also been criticized by libertarian groups who have "...castigated

\section{Making drugs that have not undergone sufficient testing in clinical trials available to the public ... runs too high a risk of violating our primary oath}

SB Hanauer is Editorin-Chief of Nature Clinical Practice Gastroenterology \& Hepatology.

Competing interests

The author declared he has no competing interests.

Reprinted from Hanauer SB (2007) Nat Clin Pract

Gastroenterol Hepatol 4: 117

www.nature.com/clinicalpractice doi:10.1038/ncpgasthep0762 the FDA for blocking access to new and ... potentially lifesaving drugs." (Jacobson PD and Parmet WE [2007] JAMA 297: 205-208). Jacobson and Parmet comment on a 'battle' in the US Court of Appeals, in which a panel of three judges opined that "...terminally ill patients have a constitutional right to purchase unapproved drugs that have successfully completed phase I testing." The FDA has appealed against the ruling, which will be argued in front of the full District of Columbia Circuit Court. Jacobson and Parmet point out that this case "... raises challenging issues regarding drug safety at the limits of scientific knowledge, the role of markets vs regulators, medical care of terminally ill patients, individual rights vs protection of public health, and the allocation of scarce resources."

In this situation, I disagree with the libertarian view. Phase I clinical trials are designed to assess the metabolic and pharmacologic actions of a drug in humans and the side effects associated with increasing drug doses. Where possible, phase I trials also provide early evidence of efficacy, which allows wellcontrolled, scientifically valid, phase II trials to be designed. Phase I trials involve only small numbers of patients, and are not designed to prove efficacy. Only $5 \%$ of cancer drugs that have undergone phase I clinical testing are approved for patient use (JAMA 297: 205-208). The interpretation of any potential benefit of drugs in phase II trials, based upon phase I trial data, is insufficient to warrant that patients-even those with a terminal illness - should take unapproved agents if they can afford to purchase them (and purchasing power becomes another issue if less-affluent individuals are precluded from access to these agents). As physicians, our oath to "First, do no harm" still applies to the terminally ill and those with intractable disorders. Making drugs that have not undergone sufficient testing in clinical trials available to the public (however 'the public' is defined) runs too high a risk of violating our primary oath. 